Научная статья

УДК 316.4

DOI: $10.18101 / 1994-0866-2021-1-82-89$

\title{
МЕЖЭТНИЧЕСКОЕ СОГЛАСИЕ В РЕСПУБЛИКЕ БУРЯТИЯ В СОВЕТСКИЙ ПЕРИОД
}

\section{(C) Чимитова Ирина Зоригтоевна}

кандидат социологических наук, доцент, Бурятская государственная сельскохозяйственная академия имени В. Р. Филиппова Россия, 670024, г. Улан-Удэ, ул. Пушкина, 8 rindaol@mail.ru

Аннотация. Межэтнические отношения в Республике Бурятия отличаются стабильностью. В статье рассматривается взаимодействие в советский период двух крупнейших по численности народов региона — бурят и русских, составлявших подавляющее большинство населения и поэтому называемых основными в аспекте согласия. Для взаимодействующих субъектов согласие является внутренней установкой и насущной необходимостью. В содержание этого понятия входит сходство представлений, основных целей, ценностных ориентаций, межличностное и межгрупповое доверие. Все эти признаки были присущи межэтническим отношениям в Бурятии в советский период. Политическим курсом Советского Союза был интернационализм, который последовательно воплощался как управленческий принцип. Наряду с пропагандой позитивных ценностей и моделей поведения в соответствии с этим принципом унифицировались все сферы жизни общества, в том числе этническая самобытность. Вместе с тем власть поддерживала некоторые проявления этничности. В Бурятской АССР интернационализм был реальностью, т. к. отражал сущность взаимоотношений этносов на протяжении веков, а также выступал и как проявление дружбы народов, формируемой и сформированной в стране в советскую эпоху. В республике отсутствовало предубеждение между людьми по признаку их национальной принадлежности, отчасти потому, что многие представители основных этносов - потомки смешанных браков. В советскую эпоху многие коренные жители Бурятии говорили (и говорят в наши дни): «мы все тут сроднились», что вполне отражает максимальную близость посторонних друг для друга людей как субъектов межэтнической коммуникации. Обозначением позитивных отношений на разных этапах истории межэтнического взаимодействия стало понятие «согласие». В настоящее время это понятие проходит процесс концептуализации, что открывает определенные перспективы, в том числе и в плане использования нового инструментария исследования межэтнической коммуникации.

Ключевые слова: межэтническое согласие; межэтнические отношения; межэтническая толерантность; этнос; буряты; русские; советский период.

\section{Для цитирования}

Чимитова И. 3. Межэтническое согласие в Республике Бурятия в советский период // Вестник Бурятского государственного университета. Философия. 2021. Вып. 1. С. 82-89. 
Межэтнические отношения в одном из субъектов РФ, Республике Бурятия, в течение продолжительного времени отличаются стабильностью. Обратимся к рассмотрению взаимодействия в советский период, по-прежнему в значительной степени определяющий нынешнюю ситуацию в межэтническом взаимодействии двух крупнейших по численности народов этого региона, бурят и русских. По данным Всесоюзной переписи 1937 г., 29,3\% населения республики составляли буряты, $64,1 \%$ - русские.

Прежде всего в то время имела место преемственность между отношениями сотрудничества, взаимопомощи, добрососедства, доверия, дружбы, сложившимися за несколько веков проживания на одной территории и ставшими традицией, и актуальными для советского периода реалиями в данной сфере.

Национальная политика Советского Союза, проводимая и в Бурятской АССР, проанализирована достаточно объективно [1; 2]. Вместе с тем небезынтересно рассмотреть взаимодействие основных этносов в указанный период в аспекте согласия, но прежде необходимо кратко уточнить содержание ключевого понятия.

Раскрывая содержание понятия «согласие», А. С. Панарин, В. И. Самохвалова и некоторые другие авторы подчеркивают, что оно - атрибут серьезных отношений участников взаимодействия, внутренняя установка и насущная необходимость [3, с. 31-32]. Эти признаки коммуникации действительно свойственны согласию.

Согласие, как считает Л. М. Дробижева, есть не только готовность принять других и взаимодействовать с ними, но предполагает и «некий объем общих, сходных представлений, основных целей в поле действий» [4, с. 93], «межличностное и межгрупповое доверие, согласованные ценностные ориентации» [5, c. 81].

Наличие общих, сходных, согласованных представлений, целей, ценностных ориентаций, а также доверия между основными этносами Бурятии обусловлено столетиями добрососедских отношений между ними.

Доверие «формируется на основе определенных норм и правил, относительно которых сложился социальный консенсус, и выступает непременным условием длительных и стабильных социальных отношений. Культура доверия необходима для успешной политической самоорганизации общества, а его виды обобщенное, межличностное, межгрупповое доверие - выступают основополагающими факторами социальной консолидации и межнационального согласия» [6, с. 37].

Одним из направлений политического курса СССР с первых десятилетий его существования стал интернационализм, и он последовательно воплощался в стране в последующем как управленческий принцип, опираясь на соответствующую идеологию, которая, среди прочего, абсолютизировала его классовую природу. Наряду с пропагандой ряда позитивных ценностей и моделей поведения в соответствии с этим принципом унифицировались все сферы жизни общества, в том числе этническая самобытность; в качестве приоритетной была объявлена цель создания новой исторической общности - советского народа. 
Вместе с тем власть развивала и поддерживала некоторые проявления этничности. В рассматриваемом регионе, как и на других аналогичных территориях, была создана автономная республика, осуществлена коренизация аппарата управленческих структур, преодолена экономическая, политическая, социальная и культурная отсталость бурят, эвенков и др. аборигенных этносов, малочисленные народы поддерживались государством, были достигнуты значительные успехи в просвещении, науке, культуре и т. д. По мнению Г. Абдулкаримова, в советское время имела место преемственность направленности дореволюционной политики государства на сохранение, с некоторыми изменениями, на периферии исторически сложившихся этнокультурных комплексов, на предоставление ей «относительной автономии в реализации этнокультурных интенций» $[7$, c. 277,274$]$.

Репрессии 1930-950-х гг. катастрофически проявились в Бурятии: она была разделена на республику и два автономных округа, но часть ее прежней территории с компактно проживающим аборигенным населением вошла в состав соседних областей; репрессиям подверглись представители всех национальностей, классов и слоев населения.

Непоправимый урон не слишком многочисленному титульному этносу трех новых субъектов РСФСР нанесло физическое и моральное уничтожение наиболее активных, богато одаренных, искренне стремившихся служить стране и народу, убежденных в правоте идеологических постулатов того времени представителей бурятской интеллигенции, деятельность которой могла бы способствовать более эффективному и всестороннему развитию республики и округов, что, вполне вероятно, помогло бы Республике Бурятия и бывшему УстьОрдынскому Бурятскому автономному округу избежать нынешнего статуса территорий, которым свойственны депрессивность и дотационность.

В эти же годы в Бурятии, как и в других национальных образованиях, осуществлялась коллективизация и индустриализация, сопряженная со значительным притоком рабочей силы из центра и других регионов страны, произошли коренные перемены в сфере духовной культуры. В результате модернизации уклада и образа жизни подверглось трансформации традиционное аграрное общество, а этничность аборигенных народов сосредоточилась главным образом в сфере культуры.

Здесь, как и в других сферах жизни общества, несмотря на официальный лозунг о расцвете социалистических наций, имели место пренебрежение национальной самобытностью и ассимиляция. Происходила унификация и стандартизация, однако необходимо учитывать, что за это «ответственна» не только советская система, - данные процессы, как правило, сопровождают большинство форм модернизации, а советский проект, безусловно, был модернизационным.

Что касается интернационализма, то в Бурятской АССР и округах он был реальностью, причем не столько директивно внедряемой, сколько отражавшей сущность взаимоотношений этносов на протяжении веков, выступая и продолжением давней традиции этого региона, и тех отношений между народами, мо- 
дель которой внедрялась в бытие и сознание населения официальной властью в эпоху СССР.

Несмотря на догматизм идеологии, оторванность от жизни и назойливость пропаганды и агитации, топорность в решении практических вопросов, требующих большей тонкости и вдумчивости, в том числе связанных с национальной спецификой, многие другие ошибки и даже преступления, успехи Союза ССР в разрешении национального вопроса (если исключить из рассмотрения период его недолгой агонии) общепризнаны и столь очевидны, что их не может отрицать ни один беспристрастный эксперт.

В Бурятии, как правило, отсутствовало предубеждение между людьми по признаку их национальной принадлежности, отчасти и потому, что многие представители основных этносов - потомки смешанных браков. В. И. Затеев писал: «В Бурятской АССР разнонациональные семьи по переписи 1970 г. составили $8 \%$ всего количества семей в республике, а по переписи 1979 г. - 8,9\%. Межнациональные браки и семьи - один из важных результатов тесного общения национальностей, живущих в дружбе и согласии». Автор ссылается также на результаты социологического исследования, проведенного в республике в начале 1970-х гг., согласно которому «три четверти опрошенных в целом одобрили межнациональные браки, рассматривая их как живое проявление тесного общения, дружбы и взаимного уважения советских людей различных национальностей» $[8$, с. 150$]$.

Косвенным свидетельством межэтнического согласия народов Бурятии являются итоги социологического опроса населения, осуществленного в 2005 г. и показавшего, что при оценке актуального состояния межэтнических отношений старшие возрастные группы респондентов (50-59 лет; 60 лет и старше), достаточно долго прожившие в эпоху СССР, оценивали их в основном как стабильные (76,7 и $74,9 \%$ соответственно). Что касается молодежи, то в возрастной группе 18-29 лет аналогичная оценка дана $57,2 \%$ опрошенных [9, с. 26].

Полагаем, что более оптимистические ответы представителей старшего поколения связаны с их собственным длительным позитивным опытом в сфере межэтнической коммуникации. У молодых респондентов такого опыта было меньше. Кроме того, в начале 2000-х гг. не было стабильности на Северном Кавказе, и довольно заметны были проявления национализма прежде всего в крупнейших городах европейской части РФ, что не могло не отразиться на психологическом самочувствии молодежи.

Позитивная оценка респондентами национальной политики советского периода доминировала в итогах социологического опроса населения другого региона - двух районов Ханты-Мансийского автономного округа, проведенного в 1996 г. Из числа тех, кто признавал наличие межэтнической напряженности в местах их проживания (таковых было 19,9\% от общего числа опрошенных), лишь $12,8 \%$ объясняли ее ошибками в советской национальной политике, а более чем трехкратно превышающее количество респондентов $(41,2 \%)$ - действием социально-экономических (включая политические) факторов, характерных для перестройки и реформ [10, с. 156]. По результатам этого опроса очевидна значи- 
тельно более высокая оценка жителями ХМАО решения национальных проблем в Советском Союзе, чем в 1990-е годы.

В эпоху СССР многие коренные жители Бурятии говорили (и говорят в наши дни): «мы все тут сроднились», что вполне адекватно отражает максимальную близость посторонних друг для друга людей как субъектов межэтнической коммуникации.

В перестроечном и постперестроечном дискурсе в числе других духовных ценностей советского периода подвергся переоценке и интернационализм. Сам обозначающий его термин был вытеснен другим, отнюдь не тождественным «толерантность», который со временем прочно вошел в научный оборот.

Ранее нами отмечалась необходимость терминологического обозначения интернационализма советского периода [11, с. 26-27]. В те годы ощущалась потребность в адекватном понятии для обозначения явлений этого смыслового ряда безотносительно к конкретному времени.

Понятие «толерантность» в данном случае было бы не совсем точным. Как известно, большинство исследователей считают, что сущность толерантности состоит в способности субъекта признавать различия, т. е. позитивно или по крайней мере нейтрально реагировать на непохожесть другого участника коммуникации. Не случайно при интерпретации толерантности применяются и такие термины, как «безразличие», «невозможность взаимопонимания», «снисхождение» [12, с. 48-51], «взаимно-параллельное сосуществование», «безучастное равнодушие», «формальная, в определенном смысле ритуальная, внешнеповеденческая .... категория» [13, с. 49-50].

Адекватным обозначением позитивных отношений субъектов на разных этапах истории межэтнического взаимодействия стало понятие «согласие», использовавшееся иногда и ранее, но приобретшее значение полноправного термина в начале второго десятилетия XXI в., после выхода в свет в 2012 г. статьи В. В. Путина «Россия: национальный вопрос» в рамках одной из избирательных кампании на пост Президента РФ, а также после принятия «Стратегии государственной национальной политики Российской Федерации на период до 2025 года».

В настоящее время понятие «согласие» переживает процесс концептуализации, что открывает определенные перспективы, в том числе и в плане использования нового инструментария исследования межэтнического взаимодействия.

В первом приближении можно определить межэтническое согласие как сложившиеся между этносами отношения дружбы, взаимопомощи, равноправия, доверия, обусловленные сходством основ их жизнеустройства, базовых целей, норм, ценностей и т.д., взаимопроникновением различных сторон образа жизни.

Вместе с тем логично предположить, что интернационализм, выступающий и как политика государства, и как атрибут повседневных практик подавляющего большинства населения, представляет собой несколько иное явление, чем, например, патриархальные формы межэтнического согласия в XVII в. Возможно, интернационализм, или дружба народов, есть одна из конкретно-исторических форм согласия, свойственная советскому периоду отечественной истории. 
В большинстве публикаций последних лет понятие «интернационализм» используется применительно к реалиям советской эпохи $[2$, с. $174-175 ; 14$, с. 329 346]. П. К. Варнавский называет дружбу народов идеологемой и концептом советского официоза [2, с. 198]. Действительно, понятие, созданное теоретиками марксизма, приобрело негативные коннотации в практике реализации социалистического проекта, наиболее полно претворенного в СССР.

Вместе с тем, как отмечалось ранее, в Бурятии обозначаемые данным идеологическим конструктом отношения, при всех неизбежных издержках конкретного периода, были тем не менее социальной реальностью.

Ряд исследователей признает особый вклад эпохи СССР в стабильность межэтнической ситуации в Республике Бурятия. Так, по мнению Э. Д. Дагбаева, «ровные и добрососедские отношения между основными этническими группами были обусловлены тем, что годами на забайкальской земле сложилось равноправие, особенно в советский период, когда ряд политических действий государства - автономия, политика коренизации государственного аппарата, создание культурно-социальной инфраструктуры в виде институализации бурятской науки, театра, искусства и т. д. - позволил достичь сбалансированного уровня развития крупнейших этнических групп. Историческая память народов сохранила примеры взаимопомощи и взаимовыручки, она не омрачена событиями межнациональных распрей и конфликтов...» $[15$, с. 22$]$.

К понятию интернационализма применительно к локальной ситуации иногда обращаются и при описании постсоветского времени. Так, авторы опроса населения Республики Бурятия, в том числе и по вопросам межэтнических отношений, проведенного в 2005 г., называют респондентов, имеющих близких друзей другой национальности, чем они сами, «интернационалистами» [10, с. 28].

Эти и другие аспекты данной проблемы нуждаются в дальнейшем глубоком и масштабном комплексном исследовании. Очевидно, что в повседневных практиках доброжелательность или ее отсутствие со стороны большинства этнической группы по отношению к иной группе или ее представителю зависит от базовых параметров культуры определенного конкретного сообщества, в том числе и от сложившихся в данном сообществе традиций. В Бурятии позитивные традиции межэтнического взаимодействия сложились уже давно, а в советский период лишь укрепились, и этот тренд сохранился по настоящее время.

Таким образом, межэтническое взаимодействие в Бурятии в советский период можно охарактеризовать как отношения согласия ее народов, прежде всего двух крупнейших по численности - бурят и русских, что прежде всего было обусловлено сложившимися за несколько столетий сотрудничества и добрососедства традициями взаимопомощи, доверия и дружбы этих народов, а также определенными успехами политики интернационализма, проводимой в СССР.

Литература

1. Елаев А. А. Бурятский народ: становление, развитие, самоопределение. М.: Вестком, 2000. 352 c. 
2. Буряты в этнополитическом пространстве России: от империи до федерации / Б. В. Базаров, М. Н. Балдано, О. В. Бураев [и др.]. Улан-Удэ: Изд-во БНЦ СО РАН, 2017. $320 \mathrm{c}$.

3. Самохвалова В. И. Идентичность, норма и пределы толерантности // Философские науки. 2008. № 4. С. 26-45.

4. Дробижева Л. М. Ресурс межнационального согласия и баланс нетерпимости в современном российском обществе // Мир России. 2012. № 4. С. 91-110.

5. Дробижева Л. М. Потенциал межнационального согласия: осмысление понятия и социальная практика в Москве // Социологические исследования. 2015. № 11. С. 80-90.

6. Мукомель В. И., Рыжова С. В. Доверие и недоверие в межнациональных отношениях // Социологические исследования. 2017. № 1. С. 37-46.

7. Абдулкаримов Г. Теоретические проблемы актуальной этнополитики в России: этносоциология модернизации современной России. М.: Весь Мир, 2008. 336 с.

8. Затеев В. И. Диалектика национальных процессов в СССР. Улан-Удэ: Бурят. кн. изд-во, 1989. 160 с.

9. Межнациональные и этнические вопросы Бурятии / Ц. Б. Будаева, Л. И. Итигилова, 3. Р. Мэрдыгеева [и др.]; отв. ред. А. А. Елаев. Улан-Удэ: Изд-во ВСГТУ, 2006. 132 с.

10. Мархинин В. В., Удалова И. В. Межэтническое сообщество: состояние, динамика, взаимодействие культур (по материалам социологического исследования в районах традиционного северного природопользования коренного национального и русского старожильческого населения Ханты-Мансийского автономного округа). Новосибирск: Наука. Сиб. издат. фирма РАН, 1996. 191 с.

11. Чимитова И. 3. Межэтническая толерантность: сущность, характер и особенности проявления в Республике Бурятия. Улан-Удэ: Изд-во БГСХА им. В. Р. Филиппова, $2011.138 \mathrm{c}$.

12. Лекторский В. А. О толерантности, плюрализме и критицизме // Вопросы философии. 1997. № 11. С. 46-54.

13. Самохвалова В. И. Понятие толерантности и его содержание в современном культурном контексте // Толерантность в культуре и процесс глобализации / Учреждение Российской академии наук Институт философии РАН, Академия гуманитарных исследований. М.: Гуманитарий, 2010. С. 32-53.

14. Синявский А. Д. Основы советской цивилизации. М.: Аграф, 2002. 464 с.

15. Дагбаев Э. Д. Социокультурное развитие бурятского сообщества в начале XXI века // Бурятская литература в условиях современного социокультурного контекста: материалы регион. науч. конф. (27-28 ноября 2006 г.). Улан-Удэ, 2006. Ч. 1. С. 14-26.

Статья поступила в редакциио 18.11.2021; одобрена после рецензирования 25.02.2021; принята к публикациии 09.02.2021.

\section{ETHNIC CONSENT IN THE SOVIET REPUBLIC OF BURYATIA}

\section{Irina Z. Chimitova}

Cand. Sci. (Sociol.), A/Prof.,

Filippov Buryat State Agricultural Academy

8 Pushkina St., Ulan-Ude 670024, Russia

rindaol@mail.ru 
Abstract. Interethnic relations in the Republic of Buryatia are characterized by stability. The article discusses the interaction of the two largest nations in the region during the Soviet era, the Buryats and the Russians, who make up the overwhelming majority of the population. Consent is an inner attitude and an urgent need for the interacting subjects, this concept includes the similarity of ideas, key objectives, values, interpersonal and intergroup trust. All these features were inherent in the ethnic relations in Soviet-era Buryatia. The policy of the Soviet Union was aspired to internationalism, which had been consistently embodied as an administrative principle. Along with popularization of positive values and behaviors in accordance with this principle, all spheres of the society including ethnic identity were unified. At the same time, the government supported some manifestations of ethnicity. In the Buryat ASSR internationalism was a reality reflecting the relationships of ethnic groups over the centuries and manifested as the friendship of peoples that had been developed in the country during the Soviet era. In the republic there was no prejudice between people on their national identity, partly because many of people were descendants of mixed marriages. In the Soviet era the indigenous people of Buryatia used to say (and they say today): "We all became friends", this words reflect the maximum closeness of the representatives of different nations to each other as subjects of interethnic communication. The concept of "consent" has come to mean "positive relations" at different stages of the history of ethnic interaction. Currently, this concept is in the process of conceptualization, which opens up certain perspectives, including the use of new tools for studying inter-ethnic communication.

Keywords: ethnic consent; ethnic relations; ethnic tolerance; ethnos; Buryats; Russians; the Soviet era.

\section{For citation}

Chimitova I. Z. Ethnic Consent in the Soviet Republic of Buryatian. Bulletin of Buryat State University. Philisophy. 2021; 1: 82-89 (In Russ.).

The article was submitted 18.11.2020; approved after reviewing 25.02.2021; accepted for publication 09.02.2021. 